JOURNAL

of Health Inequalities

\title{
Invisible migrants: A micro-ethnographic account of bodily exhaustion amongst migrant manual labourers working the graveyard shift at New Spitalfields Market in London
}

\author{
Julius-Cezar MacQuarie \\ Faculty of Sociology and Social Work, University of Babes-Bolyai, Cluj-Napoca, Romania \\ Centre for Policy Studies, Central European University, Budapest, Hungary
}

\begin{abstract}
This article reports data collected during an ethnographic research project conducted in the New Spitalfields wholesale night market in London. It foregrounds and analyses the portraits of two protagonists and triangulates them with data collected in the wider project. This micro analysis reveals that low-skilled workers (loaders, drivers, cleaners, servers) of the night market engage in physical labour tasks to maintain a 24/7 city's economy appetite round-the-clock. The night workers' somatic experiences, rhythmic bodily labour that constitutes the workers' bodily capital, are discussed on the backdrop of challenges that they face while working the "graveyard" shift. The paper relays the workers' individual characteristics, such as the physical and mental abilities to endure and embody the duress of night-shift work. This paper proposes that bodily exhaustion, alienation, and sleep deprivation are amongst the factors causing precarious migrant night workers to become bioautomatons who are awake and working around the clock.
\end{abstract}

KEY WORDS: bodily exhaustion, nightshift work, migrants, sleep despoliation.

ADDRESS FOR CORRESPONDENCE: Julius-Cezar MacQuarie, Faculty of Sociology and Social Work, University of Babes-Bolyai, Cluj-Napoca, Romania, e-mail: julius.cezar.macquarie@ubbcluj.ro, imailfromdrjc@gmail.com

\section{INTRODUCTION}

This paper has been presented at the British Association for Slavonic and East European Studies 2019 Annual Conference in Cambridge, UK, as part of the panel on Healthy Body, Healthy Mind: Substance Use, Prevention, and Exploitation in Central and Eastern Europe and the Diaspora. The aim of this paper is to present the readers of the Journal of Health Inequalities with the findings of my micro-level analysis of the empirical body of one of my doctoral thesis' chapters entitled Night-Shift Work Habitus and the Six 'S' Factors. In this paper, two protagonists' portraits have been foregrounded, analysed, and their accounts triangulated with data that I collected while I was immersed in, and observed, New Spitalfields wholesale night market in London. The night workers' somatic experiences, rhythmic bodily labour that constitutes the workers' bodily capital, are discussed on the backdrop of challenges that they face while working the "graveyard" shift. I relay the workers' individual characteristics, such as the physical and mental abilities to endure and embody the duress of night-shift work.

There are two epistemological considerations worthy of noting from the outset. They underlie the methodological $^{1}$ innovation of this ethnographic account. The first point is that prior to leaving for fieldwork, my assumption was that in highly precarious environments solidarity and competition within and between groups of night-shift workers existed in a somewhat fragile

'For a comprehensive reading of the conceptual framework of my doctoral thesis see Invisible Migrants: The Glocturnal City's 'Other Workers' in the Post-Circadian Capitalist Era. Available on Central European University. Electronic Thesis Database. 
form of sociability drawn along ethnic lines. However, neither solidarity nor cooperation were enacted along ethnic lines, as I have discussed in more detail elsewhere [1]. This meant that the conclusions that I reached are in part theoretically grounded in existing anthropological scholarship on transnational migration [2-4]. Of particular importance was work by migration scholars, encouraging research with migrants living and working in global cities, and focusing on migrants' entrepreneurial networks rather than taking an "ethnic lens" perspective $[5,6]$. Thus, I did not focus on ethnic ties of solidarity, but on the ways in which migrants formed (or lacked) networks of cooperation [7].

Secondly, my work was also influenced by the exploration of the political theorist and gender scholar Lorey [8] of how precarity enters fe/male workers' bodily existence once it has invaded their households and workplaces. Precariousness among migrant night-workers is not accidental but remains largely invisible due to the nature of night-shift work. The existential precariousness (bodily, mental, and social) that migrant nightshift workers experience remains unaccounted for and is continuously reproduced, as the managing authorities do not take any responsibility for applying labour laws or sanctioning employers who abuse their workers. This three-fold phenomenon is largely marginalised. First, due to stratified labour regimes consisting of hierarchically privileged individuals who discipline manual lowskilled workers through fragmentation; second, while developed societies demand migrant manual workers, they deny migrants decent work conditions, so they experience precariousness as the norm, which is by and large invisible due to the nature of night work activities; and third, these are not only hierarchy-based differences, but also due to "gendered gaps in transnational social rights" [9-11], which results in further marginalisation of female workers.

Nevertheless, it could be said that such trends may resemble similar developments in other hemispheres. Patel's gender research framework on India's call centres reveals a "pink collar" employment domain, swaying the working nightscape. "Pink collar" means that female night-shift workers mother their children, near and away from home, and in a sense they work overtime continuously, while their work remains devalued [12]. Her findings on the feminisation of labour in India apply to the nocturnal landscape of the market in East London where I carried out my research - the nocturnal market landscape is heavily gendered. In the same vein as Patel's research, Allison found a sharp gender divide in Japan's labouring realms. Allison's long ethnographic project on the subject of "corporate fraternising in a Tokyo Hostess
Club" shows that although more women get paid work in Japan, "their social status is identified with home, child rearing, and house work" [13].

\section{MATERIAL AND METHODS}

In 2015 I immersed in my doctoral fieldwork as a participant observer at New Spitalfields market - the largest of its kind in the UK, hosting 105 stands for 120 businesses that employ over 1000 workers. It opens six nights per week, from Sunday to Saturday.

The mixed method approach combined somatic experiences with analytical precision complemented by experimental acuity through visual methods. It thus focused on the corporeality aspects, e.g. bodily practices and skills that my co-workers have not verbalised in detail [5]. More specifically, I employ visual material as an instrument of objectifying the subjective ${ }^{2}$. Namely, to objectify my emic fieldwork experience gained as an insider. Additionally, in a similar vein to Bourdieu advocating for the logic of practice theory to break through this non-verbal, empirical reality, I combine the oral with the visual in relaying this vivid, corporeal experience of researching the night work landscape. I have, however, expanded on the emic dimension of my ethnography elsewhere [15] to highlight the benefits of such an innovative approach that departs from the classical methods of researching marginalised and hard-to-reach populations.

\section{RESULTS}

This section portrays two co-workers, one female, Lexa (waitress), and one male, Logan (salesman). I foregrounded the two respondents to reflect how precariousness invades one's body (Lexa), as a result of another's significant role in the distribution chain of capital and power relations (Logan). Lexa, the café worker, is at the receiving end of physical hardship and abuse. Logan, the salesman, occupies a vital position in the hierarchical structure of the market. He holds a significant role in how precariousness is distributed onto the manual labourers. Though Logan was not responsible for creating a precarious and abusive work environment for Lexa, he contributed to others (not mentioned here) through the ways described later. The micro-analysis, in-brief here, follows my emic enactment of the phenomenon of night-shift work ${ }^{3}$ precariousness among migrant manual labourers. However, for the unabridged accounts of the two portraits see [15].

\section{LEXA, WAITRESS IN A MARKET CAFÉ}

Lexa, age 20, is Romanian café server at New Spitalfields night market. In 2015, when I interviewed her,

\footnotetext{
${ }^{2}$ I discuss in-depth the role of visual methods in migration studies and the lessons learnt from combining research with film-making in this book chapter: Researcher's Nightworkshop: A Methodology of bodily and cyber-ethnographic representations in migration studies [15].

${ }^{3}$ For details on the corporeality experiences that I enacted as a nocturnal anthropologist see this presentation. Available at: http://bit.ly/blckbstr2. Accessed: 25.06.2019.
} 
Lexa had already been working at New Spitalfields night market for six months. Her shift patterns and length of time spent at work comprised the usual 11-12-hour night shift, from around 9:00-10:00 p.m. until 9:00 a.m. Lexa had no previous experience of working in a café. In the first few weeks, she helped in the kitchen to prepare fast food. She told me that she was planning to reunite with her daughter, whom she had to leave in her mother's care in southern Romania. Lexa had finished secondary school, but her high-school diploma was not sufficient to allow her to find a decently remunerated job in Romania ${ }^{4}$.

In the first couple of months, Lexa spent her days working as a janitor and cleaning hotel rooms and her nights selling hot drinks and food, living on a few hours' sleep in the 24-hour cycle. Constrained by her limited free/sleeping time, Lexa's concern to earn money grew with every minute of her waking hours. She was determined, despite the hardships, to save enough to bring her small daughter over so they could live together in the UK.

Working in two places... I began to feel it on my body. I am dependent on this energising drink, which is not healthy. I drink it daily because of the physical exhaustion. Working nights meant that I tried to rest in the day. My life was spent on work, sleep, work, sleep. I was physically exhausted. I could not keep up anymore. So, I missed one shift. He cut two nights' worth of my pay. This is not normal. I stopped working for him.

In part, Lexa's story coincides with Bourdieu's claims that "in all conceivable circumstances of a type, a particular set of agents will behave in a particular way" [16]. One may assume that Lexa arrived at the market with a habitus built in her previous "stigmata of experience" [17] in her time spent working at a casino in Romania, where, as she explained, "nobody cares either". Her vulnerability in Romania became her strength as she was driven by the desire to reunite with her daughter, regardless of whether anyone cared and regardless of the hardships she would need to overcome.

The precarious stage that Lexa was at when the abuse took place indicates that when migrants arrive in a new work environment without access to support from a community, they become victims of repeated abuse because they cannot take the stance they wish they could, such as denouncing the abuser. Instead, on numerous occasions precarious migrants return to abusive managers and beg for their jobs back. Lexa experienced the same pattern. She too returned and begged her boss to hire her between 2015 and 2017, when I last saw her.

Consequently, the precarious migrants perpetuate their own vulnerability by refusing to engage in pathways that would help bring about, in the long term, their social, legal, and economic protection. I observed a set of combined factors that facilitate manual migrant workers' trajectory from precarious workers to abused victims. Among these, family debts and responsibilities, no employment contract, and not declaring taxes are most common. Another factor, Lexa thinks, lies in the workers' attitude:

Market employers keep hiring one girl after another, in this illegal way. I work at this café. They pay me cash-in-hand, without a contract. Elsewhere, jobs are paid worse than mine. The problem is with us for accepting to be paid so little.

One morning, on the way to the underground, she said to me that the café owner had made indecent proposals to her, but she had refused him. Having not succeeded in that way, he then began talking inappropriately to her and in front of other colleagues - two other migrant women whom I observed whilst I was working for this café manager. But, I never saw him misbehaving towards me (another male) or against the other two English females who briefly worked there - Lexa was the target of his persecutions; in other words, he has distributed the workload differentially, at his discretion. The way in which he would extract the maximum gains out of her bodily capital included (but were not limited to): demanding unpaid overtime, ordering her cleaning chores, and serving tasks in a disproportionate ratio to her co-workers. Lexa described to me how being sexually harassed in the workplace only worsened the abusive experiences from her employer (whose acts of abuse I witnessed while I was her co-worker).

\section{LOGAN, THE SALESMAN}

Logan, a salesman in his mid-30s, is from Turkey, and a naturalised British citizen. Logan arrived from Turkey as a teenager to join his sister, who was already living in the UK. Every summer holiday he spends up to six weeks in Turkey. During his 17 years of work at New Spitalfields market, Logan has divorced twice and is now single. His children live with his first ex-wife in London, and he visits them regularly. Logan had only been educated up to year 10, when he arrived in the UK at age 16. He had no professional background at the time, but he had spent most of his working life trading at Spitalfields market for Turkish-owned companies. He assured me that he pays all his taxes. It is worth noting that, at Spitalfields market, some irregular migrants cannot pay taxes, so their income is quasi-undeclared earnings. However, both EU citizens and regular migrants who earn undeclared money work irregularly because they are breaking tax and immigration regulations.

In Wacquant's words, Logan's 17 years of night market work are "stamped by membership in the collectives and

${ }^{4}$ The national minimum wage in Romania is so low that she could not see herself prospering as a casino employee, a job which she did after finishing high school (Romanian Government, 2017). Decree No. 846/2017 states that from January 2018, the minimum wage in Romania increased to $€ 408.80$ ( $£ 366.55$ per month) or $€ 2.45 / \mathrm{h}$ ( $£ 2.2$ per hour; $1,900 \mathrm{RON} /$ month or $11.40 \mathrm{RON} / \mathrm{h})$. Available at: http://bit.ly/mmuncii_ro. Accessed: September 2018 . 
attachments to institutions" [18]. He is $100 \%$ committed to the job that he feels he was "sociologically destined for" from the moment he set foot in the market at the age of 16 [16]. By the same logic, Logan has "sedimented" the habitus of night-shift work, and "reaps the rewards" [20]. I foregrounded Logan in this article due to one main criterion: he depicts practices that Lexa or other manual workers could not have engaged in, as manual labourers who are unable to claim their rights to fair and just working conditions. By prioritising business needs over workers' rights and working conditions Logan is defending and applying a business model whereby capital is extracted with least possible investment in the employees. This means that, although he had once been at the receiving end of an employer's abuse, now he occupies a higher position in the hierarchy of market trading. In this way, the habitus of night-shift work cannot be fruitfully analysed without Logan since he represents "settings that inculcate, cultivate, and reward distinct but transposable sets of categories, skills, and desires among their participants" [20]. $\mathrm{He}$ is integrated into a hierarchy dominated by male managers and owners. His absolute position dictates the rules for other workers - when and where they can eat or if they can leave the shop floor at nature's call. Logan can override that call if and when he wishes so.

You get breaks when there is nothing to do, when the stand is not busy. They are human beings, like us; there is no difference between us and the loaders or porters [forklift-truck drivers]. If there is a break, let them have it. But they've got to realise it! They've got to appreciate it!

While he shares collective experiences with other night-workers, his individual experiences set him apart from others - he is the embodiment of the institutional presence through organisational labour discipline practices. In the next vignette he sets an example to the crew he manages.

I like to know where my crew is - in the toilet, at the café. So, if I am going to the toilet, I'll tell my boss, so he keeps an eye [on the stand].

As a participant observer, I became an insider with access to the backstage, to put it in Ervin Goffman's words in Presentation of the Self. During market peak time, I was subject to and saw other workers not being allowed to leave the stand to buy food or drinks from the nearby café or even for toilet breaks. I shared my insights with Logan, but he disagreed with me. Of course, workers are [allowed] to respond to nature's calls, but on his terms.

\section{DISCUSSION}

The two embodied histories recounted above reveal a different set of dispositions. Lexa's bodily exhaustion, and physical and mental abuse are at the opposite end to Logan's. His role transgresses between manager's responsibilities to fragment and discipline the workers, and salesmen who puts business interests above workers' rights. Together they depict a highly gendered landscape with males in dominating positions and women experiencing abuse and precariousness.

Lexa was the most precarious worker I encountered in 2015. There are several reasons for this: inexperience with night work, carrying out an auxiliary type of service, and lacking in English language skills. She shares with others the hardships of market night-shift work in an unregulated environment. More notable in her case is the abuse that she suffered from her employer. Despite her determination, the problems that she faced during such a short period tested her ability to endure the precarity landscape of the night market.

Logan depicted a set of skills that crystallise Lexa's precariousness and that of many other manual labourers. He demonstrated an institutionalised set of skills inculcated as he progressed up the organisational hierarchy. As salesman and floor manager, he makes his decisions based on business needs and not workers' rights and needs, i.e. not from the conviction that they are entitled to rights (to decent work conditions), but on the basis that they should be appreciative of his indulgence, when he thinks they deserve it. However, Logan does not seem to draw any satisfaction from the power he holds over his workers. He acts in a specific manner because he follows a particular work ethos practised within the social landscape of the market. Although, he is the less precarious of the two actors - not detached from the privileges he holds, the role that Logan has in disciplining (i.e. controlling the time and freedom of) other workers is indispensable in discussions on the nature of night-shift work and characteristics of precarious work places.

Night-shift work depletes the workers' bodily resources. The body is first and foremost the manual worker's means of production. The body provides the means for manual labour. Therefore, manual workers need constant management of their bodily capital to perform competitively and prevent ill-being and the consequent loss of employment. However, the lack of decent working conditions explains how the broader implications of the labour regime encourage almost inhuman precariousness among "people [who] are like dead men walking', as one co-worker confessed, because, he emphasised, "night work breaks you". Night-workers are day-sleepers trapped between a life on caffeine (and other energising beverages) and daydreaming about a prosperous future. Night and day, they survive the capitalist machinery developing capital at the expense of the workers' disinvested bodies. The managing authorities' practices and mechanisms squeeze every drop of sweat out of the workers' physical body and soul to turn it into capital. 
Feminist scholarship acknowledges that migration policy has responded positively to the gender dimension of less fair and just migrant worker practices, but the gendered gaps in transnational social rights have been overlooked in migration studies [9-11]. This may explain the unexplained differences between these two protagonists as ones of gender, not only of hierarchy. The scope of this article has not been to tackle the forms of expression of power when considering the gender dimension apart from position in the hierarchy, and I propose two objectives for further investigation to address this limitation. First, to synthesise migration literature informed by gender studies to understand the depths of precariousness impacting on bodily, emotional, and intellectual functions of undocumented migrants generally, and migrant night workers specifically; consequently, the second objective would entail critically utilising gender-based typology to explore differences and similarities in the bodily experiences of fe/male migrant workers. Last, if scholars of gender studies, ethnic relations, and the sociology of cooperation continue to be internationally prominent in policy agendas tackling gender equality and decent work standard issues, they will make a significant contribution to migration scholarship focused on undocumented migrants, and thus such crucial aims to narrow the gender gap in social rights for female migrants may be achieved.

\section{DISCLOSURE}

The author reports no conflict of interest.

\section{References}

1. MacQuarie J-C. Cooperation in contemporary capitalism: factors that reveal why embodied cooperation amongst migrant night shift workers is weakened. Nauchni Trudove 2019; 2 257-275.

2. Brettell C, Hollifield J. Migration theory: talking across disciplines. In: Migration theory. Brettell C, Hollifield J (eds.). Routledge, New York 2015. $3^{\text {rd }}$ edition.

3. King R. Theories and typologies of migration: an overview and a primer. Willy Brandt Series of Working Papers in International Migration and Ethnic Relations 2012; 3-12.

4. Schiller NG, Basch L, Blanc CS, College W. From immigrant to transmigrant: theorizing transnational migration. Anthropol Q 1995; 68: 48-63.

5. Wacquant LJD. Carnal connections: on embodiment, apprenticeship, and membership. Qualitative Sociology 2005; 28 : 445-474.

6. Glick Schiller N, Çağlar A, Guldbrandsen TC. Beyond the ethnic lens: locality, globality, and born-again incorporation. Am Ethnol 2006; 33 (4): 612-633.

7. Sennett R. Together: The rituals, pleasures and politics of co-operation. Penguin Books Ltd, New Haven and London 2012

8. Lorey I. State of insecurity: government of the precarious. Verso Books 2015.
9. Ezzeddine P. Who cares? (ageing, care and migration). Urban People 2014; 16 (2): 219-237.

10. Lutz $\mathrm{H}$. The new maids: transnational women and the care economy. Zed Books Ltd., London 2011.

11. Uhde Z. From women's struggles to distorted emancipation: the interplay of care practices and global capitalism. International Feminist Journal of Politics 2016; 18 (3): 390-408.

12. Patel R. Working the night shift: women's employment in the transnational call centre industry. Stanford University Press, Stanford, California 2010.

13. Allison A. Nightwork: Pleasure, sexuality and corporate masculinity in a Tokyo hostess club. University of Chicago Press, Chicago 1994.

14. MacQuarie JC. Researcher's Nightworkshop: A methodology of bodily and cyber-ethnographic representations in migration studies. In: Visual methods in migration studies: new possibilities, theoretical implications, and ethical questions. Nikielska-Sekula K, Desille A (eds.). Springer, Amsterdam [in press].

15. Macarie I-C. Invisible denizens: migrant night shift workers' fragile possibilities for solidarity in the post-circadian capitalist era. Centre for Policy Studies 2017; 4.

16. Bourdieu P. Pascalian meditations. Stanford University Press, California 2000

17. McNay L. Gender, habitus and the field: Pierre Bourdieu and the limits of reflexivity. Theory Cult Soc 1999; 16 (1): 95-117.

18. Wacquant LJD. Putting habitus in its place: rejoinder to the symposium. Body Soc 2014; 20 (2): 118-139.

19. Wacquant LJD. For a sociology of flesh and blood. Qual Sociol 2015; 38: 1-11.

20. Bourdieu P. Practical reason: on the theory of action. Standford University Press, California 1998. 